\title{
HEALTH TOURISM IN TURKEY: A STUDY ON PAPER NEWS
}

\section{Emel İşTAR ${ }^{1}$}

\begin{abstract}
The purpose of this study is to identify how health tourism is approached in Turkey and to analyze the current situation by considering paper news. Health tourism is becoming more important for countries in the economic and social aspects. Turkey is a country with many opportunities on this evolving branch of tourism. At the crossroads between East and West, Turkey is on its way to become the next "center of attraction" for the global health tourism market.

In this study, health tourism was approached initially in a conceptual framework. Then, the previous studies regarding health tourism. In the last part, the paper news related to healthth tourism was analyzed through content and textual analysis. The population of the study was composed of the online papers which broadcast their archive. "Hürriyet" which is one of the newspaper with the widest circulation was used as the sample and the news with regard to "health tourism" between July 20, 2014 - July 9, 2015 were examined. The study was conducted on 30 news there was found.
\end{abstract}

Key words: Tourism, Health Tourism, Turkey

\section{INTRODUCTION}

Health tourism has been the fastest growing service sector of our time. Health tourism has become a sector that helps everyone reach quality medical services, increases employment rate, and supports economies. The emergence of health tourism occurred in relation to the developments in medicine (Connel, 2006). Health tourism is a sector that cooperates with the tourism sector in order to provide special "cost effective" treatment to patients that need applications of medical treatment in general surgery or other fields that require special expertise (Barcavd., 2013). According to Magablih (2001), the travels in scope of health tourism have certain time periods. Health tourism is defined as travelling to other countries for no less than a day and no more than a year to get the treatment they need to get better (Barcavd., 2013).

Because of the increase in the world population, rise of quality of life, and increase in medical costs in various countries, other countries emerged as options where high quality treatments are performed with lower costs and led to the rise of the health tourism sector. Another thing that led to this emergence is that the world population is getting old.

The reasons for this situation are;

- Avoiding long waiting lists for patients

- Receiving higher quality treatment cheaper

- Reaching high technology in medicine

- Reducing cost of medical services

- Eliminating the need for chronic patients, the elderly or the disabled to go somewhere else and be treated

- Wishes to be treated in different or more suitable environments by people with addictions of drugs or other things

- The desire to travel and have cultural visits alongside the treatment

- The person's will of life and struggle to live (Ciğerdelen, 2012).

\footnotetext{
${ }^{1}$ Assistant Professor, Department Of Health Institutions Management, Faculty of Business, Düzce University, Konuralp Campus, Duzce, Turkey.
} 
Health tourism in Turkey had started either by organizations individual efforts or by the result of foreign patients' research they started to choose our country. In our country there is a misunderstanding of health tourism as if it constitutes only thermal and SPA applications. It is important to divide health tourism in to three, thermal, old age (elderly, senior) and medical tourism.

Özbek, (1991) define the thermal tourism as a tourism activity for curing (treatment) applications combined with support treatments such as climate curing, physical therapy, rehabilitation, mecanotheraphy, exercise, psychotheraphy and diet as well as various types of methods such as mineralizes thermal water baths, mineral springs, inhalation and mud baths. Facilities of these applications are called as Thermal Curing Centers or Hot Spring Treatment Centers. Old age tourism is regarded with senior travelers. Littrell, Paige, \& Song (2004) described senior travelers as becoming an important travel segment because of their level of wealth, higher discretionary income, lower consumer debt, greater free time to travel, and their tendency to travel greater distances and for longer lengths of time.Senior citizens (with 55 years old and over) represent around 25\% of the European population. They have both purchasing power and leisure time (mainly in the retirement age), thus representing a significant economic market potential.Smith and Puczkó (2009) define the medical tourism as "... travel to destinations to undergo medical treatments such as surgery or other specialist interventions... Medical tourism [...] can have two major forms: surgical and therapeutic. There is a clear distinction between the two. Surgical certainly involves certain operations(s), whereas therapeutic means participating in healing treatments." (Azakl1, 2012).

Turkey is on its way to becoming an important destination in thermal,old age and medical tourism, especially in the areas of rehabilitation, retirement homes and communities. Health tourism should not only be viewed as medical treatment. Equally as important are thermal spas, rehabilitation and retirement communities and services that cater to the elderly population. Turkey has taken important steps in developing these facilities and services.

\section{METHOD}

The aim of this research is to investigate the content of news which has the term "health tourism" in the title or text in newspapers and to analyze the current situation in Turkey. In addition, it is aimed with this research to determine the way and frequency of statements regarding health tourism in printed media. Determining the place of Health tourism in printed media would provide great contributions to the literature regarding this issue.

The World of this research has been created by the newspapers which publish their archives on internet. Being one of the newspapers that have highest circulation, Hürriyet has been evaluated as a sample and the news published regarding health tourism in the dates between 20 July 2014 and 9 July 2015 have been assessed. The research has been conducted through the 30 news that were determined in the archive.

In this research, the content analysis of data collected via document investigation has been used as method. Being a qualitative research method, the content analysis includes the systematic investigation of scanned newspaper news and printed news. Content analysis is a reading tool depending on deductive method. This analysis can be done through texts, speeches, advertisements and even through the television programs. Within this context, content analysis is a scientific research method which conducts investigation not only on 
the content of apparent, but also on the background of content and which ensures meaningful implications (Gürel\&Alem, 2010: 335-336). Categorical classification and assessment of the ideas has been done by using this method.

\section{FINDINGS}

In scanning of the news in newspaper, the data of the last 1 year (20 July $2014-9$ July 2015) were scanned by using the search engine after entering in the archive of the newspaper in website. As a result of scanning, the news which have the term "health tourism" in the title or text have been categorized in line with the remarks of experts and thus, the validity and reliability of the study have been ensured.

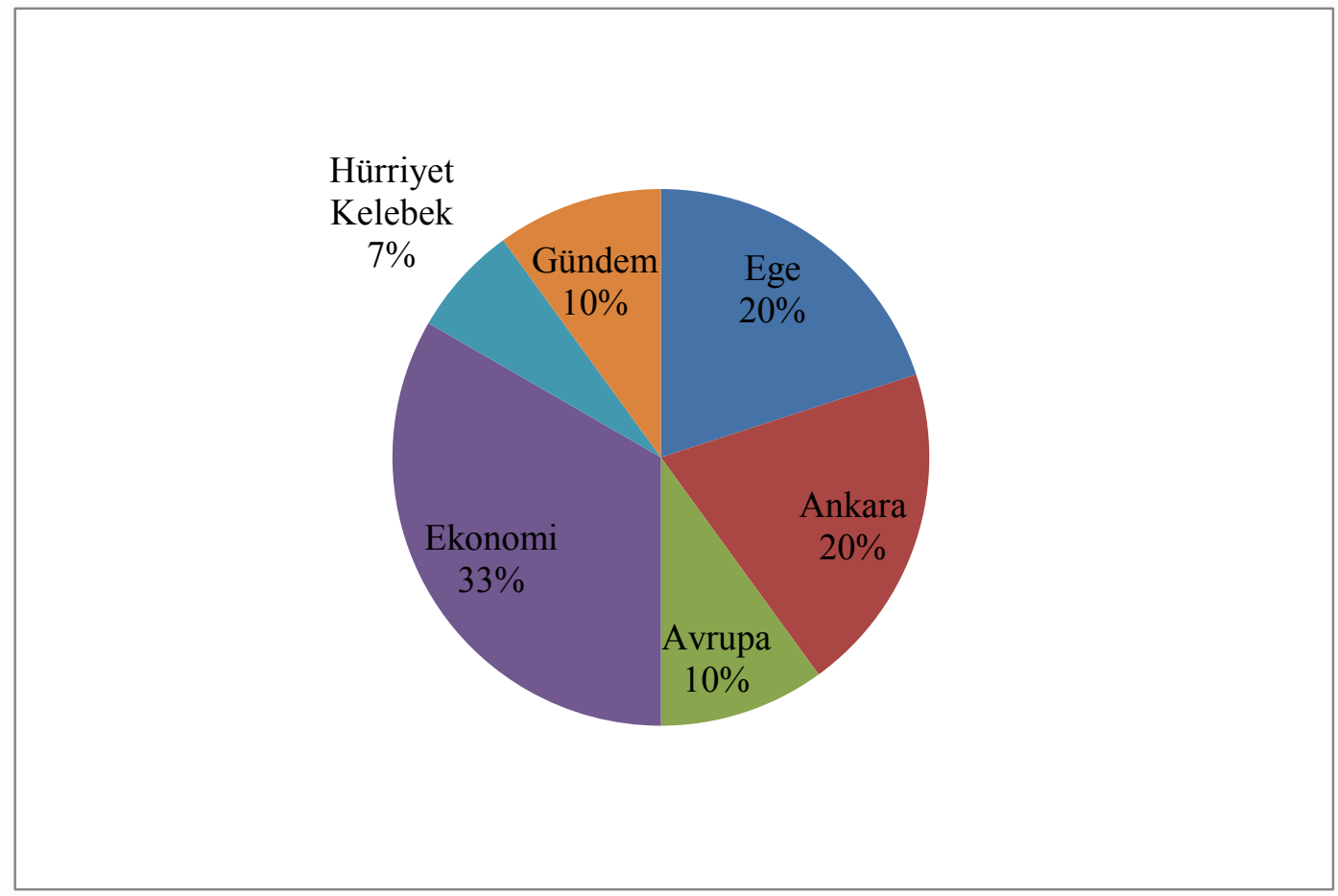

Fig. 1. The chapters where the news regarding health tourism are found

When the news including the term "health tourism" in the title or context are evaluated generally, it has been determined that this issue is mentioned in "Ekonomi" chapter at most. 10 of the 30 scanned news were given under this chapter. It has been determined that the news regarding health tourism are mentioned respectively in the chapters of Ege (6 news), Ankara (6 news), Avrupa (3 news), Gündem (3 news) and HürriyetKelebek (2 news). When the data is evaluated with the content analysis, the news bearing the term "health tourism" in the title or text have been categorized under 5 points. (see Tab. 1.). 
Tab. 1. Categories of News about Health Tourism

\begin{tabular}{|c|c|}
\hline News Category & Number of News \\
\hline International Developments in Health Tourism & 7 \\
\hline The Condition of Health Tourism in Turkey & 6 \\
\hline Economic Benefits of Health Tourism & 5 \\
\hline The Steps to be Taken for Development of Health Tourism & 3 \\
\hline Other & $\mathbf{3 0}$ \\
\hline Total & 6 \\
\hline
\end{tabular}

When the news regarding health tourism are investigated, it has been determined that most of them (9 news) are informative texts giving information about current conditions in Turkey. Then, there are 7 news mentioning about summits, conferences and fairs which are the international developments regarding health tourism. The news apart from these are mentioning about the economic benefits of health tourism (6 news) and the steps to be taken for developing the health tourism (5 news).

\section{International Developments in Health Tourism}

Turkey has been an attraction center with its strategic geographical location, its closeness to Europe, Asia, Middle East, North and Middle Africa, Russia; the accessibility to these geographies and with its developed health system. The health system in Turkey attracts the attention as the most important destination in the sector of health tourism with ists code of conduct, hospital equipments, technologic infrastructure, and trained health personnel. This important position of Turkey has started to attract attention more in international field as a result of ensuring participation into various fairs, congresses and meetings. 7 of the 30 news investigated within the research are about international developments in the sector of health tourism. In the news, the fairs, summits and conferences to which the participation has been ensured were mentioned. In the news which has the title of "Meeting for Health tourism in Ankara" (Hürriyet, 10 June 2015), it has been stated that in his speech before 160 people coming from more than 20 countries as 10 of them from Balkans, the President of World Health Council and Turkey Health Council has mentioned about the service quality of hospitals in Ankara and about the technologic competences in health sector and thus, the attention has been attracted to the potential of capital in health tourism sector. In the news, it has been seen that many countries are willing to cooperate with Turkey in the sector of health tourism. One of them is Sincan Uyghur Autonomous Region that is dependent to People's of Republic of China. In the news titled as "Health Investment from Urumqi" (Hürriyet, 6 Haziran 2015), the satisfaction taken from the condition that "Traditional and Integrative Medicine and Application Center" is going to be established in Kizılcahamam which gives services for the art of medicine of Uyghur and China with the protocol that was signed between "UrumçiTarım A.Ş." and "YıldırımBeyazıt University" in has been stated. 
The fields of health tourism where each country has expertise are different from each other. Turkey promotes its expertise in the fairs to which the participation has been ensured and thus, tries to attract tourist from other countries. In the text titled as "Attack Towards Africa in Health Tourism" (Hürriyet, 20 May 2015) the participation of Managing Director of an hospital who is also thePresident of Health Tourism Works Council under the Foreign Economic Relations Committee, with a board into Africa Health Congress and Fair that was organized in Johannesburg city of Republic of South Africa. In the text, it has been stated that the board had information exchange on health system of Republich of South Africa, public and private health financing models, the place of private sector in World health tourism market and the patient flows from sub - Saharan countries to this country. In the news, it has been pointed that the centers for infectious diseases, transplantation, trauma, brain surgery, ambustion and pediatrics are developed and wide spread and on the other hand; Turkey is in advance in the fields of liver transplant, brain surgery and hip prosthesis. In the fair, it has been underlined that South Africa is willing and open to send patients to Turkey. Turkey has been participating into various fairs in various regions to promote its "health tourism". One of these fairs is "Berlin Fair". In the text titled as "The Target of Turkey: Health Tourism" (Hürriyet, 4 March 2015), the speech of Ministry of Culture and Tourism Undersecretary has been shared. In news, the Undersecretary has stated that "We are strengthening our infrastructure in thermal and medical sector. We give importance to Health Tourism. The steps to ensure the opportunity of having rest while being treated for our guests shall be continued. In addition, we work on old - age tourism. As the life standards have increased, we aim to host the retired people for a long rime. The options for longer and more extensive holidays shall be provided.", "We attach importance to German markets. We hosted 5 million 250 thousand of guests from Germany in the past year. Our target is to increase this amount for more than $5 \%$. Besides the sea, sand and sun; we conduct our infrastructure studies to increase the attention for culture and history tourism. Each region of our country have been reconstructured to host guests" and the importance of German tourists was also mentioned. In the news titled as "Turk Tourism promoted in Londra" (Hürriyet, 4 November 2014), it has been stated that the developments of Turkey in the sector of health tourism are also promoted in addition to the the historical heritages that are found in the UNESCO list, sea tourism centers,folkloric features, in the World Tourism Market which is organized in England with the participation of more than 180 countries and is visited by more than 50 thousand people.

The international fairs and meetings about health tourism are not only held in abroad. There are serious organizations held in country. In İstanbul, Brand in Tourism \& Gastro Conference'" has been organized in the dates between 24-25 March 2015 which is defined as the biggest meeting of Tourism and Gastronomy sector and the World famous names of sector have convened in there. In the news titled as "Tourism Leaders to Meet in Ístanbul" (Hürriyet, 20 February 2015), the issues such as health tourism, rapidly growing food drink tourism, the stories about branding in toursim, the supply chain system in hotels, social media tendencies and the importance of training and Franchise in branding have been narrated by general managers and CEO's. Another organization which was included in the news and organized in İstanbul is "İstanbul Health Expo - Medical product, Hospital Equipment, Health Informatics and Technology, Laboratory Systems, Residential Care Products and Health Tourism Fair" that was organized in the dates between 10 and 13 December 2014. In line with the news titled as "Innovation Competition in Health Fair" (Hürriyet, 4 November 2014), many innovative product which can contribute to 
development of health tourism as ranging from new head guard communication system that is produced for Ambulance Emergency Action motorcycles to new intraocular lens implants has been exhibited in the fair.

\section{The condition of Health tourism in Turkey}

Health tourism has been categorized under three branches as medical, thermal and old age tourism in the World. Turkey has great advantages especially in terms of thermal tourism. Turkey has a worldwide potential in terms of geothermal sources and it is the leader with its source potential in Europe and it is the third with its hot spring practices. Having more than 1500 resources of which temperatures are changing between $20-1100 \mathrm{C}$ degrees and of which flow rates are changing between 2 - 500 lit / sec; our country has been evaluated among the first seven countries in the World thanks to its source richness and potential. (http://www.ktbyatirimisletmeler.gov.tr/, 10.09.2015) Bu özellikleri nedeniyle Türkiye'de termal tourism oldukça önemli bir konuma sahiptir.

In 4 of the 8 news showing the condition of Health tourism in Turkey, the importance of thermal tourism in Turkey has been mentioned. Among them, in the news titled as "Changing the Faith of Çeşme" (Hürriyet, 23 June2015), it has been stated that a company with 60 partners participated in a tender for thermal tourism in Çeşme has rented an approximately 85 decare of field for 35 years. It has been stated that the company will build a great thermal facility which will have Aqua Park, aesthetic surgery, treatment cure center, swimming pool, nursing center for old persons, hotel and comprehensive sport fields with 40 million dollars of investment. In the related news, it has been stated that the dead - season in Çeşme will give place to vitality, the number of qualified tourists will increase and the foreign tourist will be attracted through this region.

Thermal tourism has a great potential in Aegean Region in Turkey. In the news mentioning about this issue which has the title as "We should make use of thermal sources" (Hürriyet, 26 September 2014), it has been stated that 410 of approximately 1300 thermal sources in Turkey are prominent in terms of health tourism with their flow rates and heats; 123 of these 410 thermal sources are in Aegean Region. In the news, it has been indicated that the tourists coming for health tourism also come to Aegean Region for holiday and thus, there should be an arrangement by avoiding from the appearance of hospital except for the clinic centers. It has been expressed that the foreign tourists do not want to feel themselves as if they are in a hospital and thus, the natural structure should be protected in the regions where the thermal facilities are located and avoiding from over - structuring is important. In the news regarding thermal tourism given in newspapers, not only the Aegean Region, but also the potential of Ankara and Tunceli has been attracted. In the news titled as "Branding with Health Tourism" (Hürriyet, 26 March 2015), the place of Ankara in health tourism has been mentioned: It has been indicated that the districts ofAyaş, Beypazarı, Çamlıdere, Çubuk, Güdül, Haymana, Kazan, Kızılcahamam and Polatlı are very rich by thermal sources. In the news titled as "Pertek to develop with thermal tourism" (Hürriyet, 12 December 2014), the situation that the thermal facilities in Pertek city of Tunceli attracts tourists. In the news, it has been indicated that the thermal water, of which temperature reaches to $37-40$ degree, provides remedy for many diseases with the minerals inside and also, the thermal water is "natural mineral water".

It has been stated that, $\mathrm{i} n$ the thermal facilities which are 250 meter distant from Pertek ferry dock and which have 446 thousand square meter of indoor area, there are semi Olympic pools, kiddy pools, aqua park, thermal pools, family baths, Turkish bath and 
sauna; and the thermal water is good for many diseases such as the joint disorders and bone loss, gastroenterological diseases and dermatologic disorders such aseczema, psoriasis and acne.

Turkey has important progresses not only in the sector of thermal tourism, but also in sector of medical tourism. As some of the medical expenses have been ejected from the insurance coverage, because of economic crisis in Europe, this has caused people living in there to get treatment from countries where the medical expenses are low. Turkey is one the first - preferred places among these countries. On the other hand, Arab tourist also prefers Turkey both because of geographical closeness and the low prices. In the news titled as "Both business and holiday" ( Hürriyet, 3 December 2014), it has been indicated that in 2014 when there is the decrease in the number of European tourists in recent years; there is a serious increase in the number of people coming from Iran and Arab bazaars and also Turkey becomes more than a country of sea, sand and sun thanks to the investments and promotions and continues its claim in world health tourism market. In the text titled as "Pamukkale not leaving the summit" (Hürriyet, 16 October 2014), it has been indicated that the ones who attribute great attention to Denizli for health tourism are respectively the tourists from Russia, Germany, England, China and South Korea.

Turkey is a country which takes substantial steps in medical tourism, especially in transplantation in recent years. This issue has been mentioned in the news titled as "Remigration started in transplantation" (Hürriyet, 13 February 2015). In the news, it has been stated that the bone marrow transplantation problem has been solved in Turkey and the doctors do not send the patients abroad for treatment no more and the patients from abroad come from Turkey. It has been expressed that the bone marrow transplantation problems are solved in the country thanks to the incentives and supportive approaches of both the Ministry of Health and SSI (Social Security Institution) at the end of 2014.

When the news regarding the condition of health tourism in Turkey are investigated, it has been determined that the country has a great potential in old - age tourism, too. Especially the increase of population rate of group constituted by people over 65 to total population in countries in Europe and Far East emerges various medical expenses and various treatment processes for old aged people. Within the scope of old age tourism, the sightseeing tours, rehabilitation services, various therapies, elderly care in nursing homes and special travels and nursing services for people with disabilities are found. Among the investigated news, in the text titled as "Turkey is the lifesaver for aging Europe" (Hürriyet, 23 November 2014), it has been stated that Turkey has many advantages in equality of opinions for elderly care tourism. It has been stated that many elements such as accessibility, economic service and health procurement, experiencing the four seasons, young labor force population, widespread academic staff and hospitality can be listed among these advantages and elderly tourism can provide great acquisitions for our country. In the text titled as "Cure Holiday for Japan"(Hürriyet, 4 November 2014), it has been indicated that elderly Japan people are going to start to get service from nursing and old age asylum and facilities in Ankara by 2015 in line with the protocol signed between DÜNYADER and Japan - Turk Economic Development and Cooperation Foundation. In the news, it has been noted that the protocol shall be valid for 10 years and this will ensure the arrival of 50 thousand of old Japan to Turkey in the first 5 years. 


\section{Economic Benefits of Health Tourism}

The development of health tourism in Turkey provides great benefits to the country. Among these benefits, the increase of information sharing among countries, development of partnerships, ensuring the technology and information exchange among countries and making contribution to development of international relations can be provided. However, the most important contribution of health tourism to our country is the high economic benefits. When the reports were investigated, it has been determined that 6 of 30 news are about the economic benefits of health tourism.

Turkey is a country with high potential for gathering economic income especially in thermal tourism sector. This situation has been evaluated in the news titled as "Uşak reaches to new thermal facility" (Hürriyet, 23 March 2015) and it has been narrated that 10 million liras of investment is going to be made to the region following the allocation of Hamamboğazı Thermal Touristic Site which is idle in Banaz District of Uşak to municipality andit is aimed to provide the economy in city by enliven the thermal tourism. In the text titled as "Naomi Campbell starting trade in Bodrum" (Hürriyet, 6 January 2015), it has been mentioned that not only the thermal facilities, but also the detox centers can be investment tools in the health tourism sector in this country. In the news, it has been stated that being a famaous model, Campbell wants to purchase a detox center in Bodrum and it is remarkable that the people who prefer such centers are very rich and powerful in economic aspect.

Tourism is an important source of income for national economy in Turkey. In the news titled as "Fiscal deficit is removed with health tourism" (Hürriyet, 27 September 2014), it has been stated that the health tourism income for 2013 is 2,5 billion dollar and the expectation for 2014 is around 5 billion dollar. In the news, it has been indicated that the tourist coming for health spends 10 times more money when compared to normal tourist and this amount can be increased to 10 billion dollars when required measures are taken in $2-3$ years and a great contribution to national budget can be made by meeting the 18.6 billion TL of budget of Ministry of Health for 2014 by health tourism. In the news, additionally, it has been expressed that we have a geographical location which appeals for approximately 1 billion people including Russia, Turkic Republics, North Africa and Middle East and as a result of embargo of Iran, we can gather great income in health tourism as tourists coming from Syria and Iraq prefer Turkey for health problems they live as a result of war. In the news titled as "The number increases every year"(Hürriyet, December 2014), the economic benefits of health tourism were mentioned and it has been stated that the number of tourists coming for health tourism is more than 500 thousand and in addition, the contribution of this situation to national economy with side sectors is reached to 5 billion. In the news, it has been indicated that İzmir and Aegean region host patients from every countries around the World not only for aesthetic surgery and dental treatments, but also for advanced Technologies such as robotic surgery and "know how" applications that are used in a range including obesity and renal denervation surgeries that are done for diabetes and hypertension, for ear implants, for in vitro fertilization and transplantation. It has been underlined that an endorsement equal to the entire exportation item of Aegean Region (approximately 20 billion dollar) can be earned from health tourism alone.

In the investigated report, it has been stated that the tourists coming for health tourism spend more money when compared to other tourists. That is because they make expenses not only for holiday but also for health care services. Regarding this is issue, in the news 
titled as "European people turned the route to Turkey" (Hürriyet, 30 November 2014), it has been indicated that more than 30 million annual tourists did not increase the tourism income as expected; however the arrival of 1 million people coming for health tourism provided more than 30 million tourists. Because of this economic value, the Ministry of Health also aims to reach a Turkey that is a brand in this sector. This target was expressed in the news titled as "If you went to this hospital, they may knock your door" (Hürriyet, 16 January 2015) as Turkey will gain $9-10$ billion in 2018 and $20-25$ billion dollar in 2023 in health tourism services.

\section{Things That Can Be Done to Improve Health Tourism}

The increasing importance of health tourism in Turkey in recent years, led the government to include it in the economic plan. It has been reported in the news article entitled "Important Statements by Prime Minister Davutoğlu" (Hürriyet, 4 November 2014) that the government declared an "economic structural transformation plan" and the things that can be done to improve health tourism is among the 9 main titles in the plan. Two main titles were included in the plan as the plan on structural transformation in health industries and the plant to improve health tourism. The details of the plan were outlined in another article entitled "We will transform with our spirit" (Hürriyet, 6 November 2014); and it has been reported that a special model of producing blood plasma will be developed and it will be done under a partnership of the Turkish Red Crescent, a foreign firm and a domestic firm. It has been reported that, in scope of the plan, legislative adjustments would be made about health tourism till the end of the year 2014; a database would be formed, an implementation to apply a different price policy to patients visiting Turkey from outside would be developed and elderly tourists would be considered among priorities. In the month these news articles were published, the Action Plan to Improve Health Tourism was published in scope of the Tenth Progress Plan (2014-2018) and details of the steps were included(http://dap.gov.tr/yeniDosyalar/Kaynaklar/odop/11.pdf, 10.09.2015). Commercial chamber chairmen also stated their opinions about the improvement of health tourism in the news. In the article entitled "EkremDemirtaş Invited Erdoğan to İzmir" (Hürriyet, 15 December 2014), the chairman of İzmir Chamber of Commerce (ITO) stated that tourism, especially health tourism should be diversified and Turkey's image as a safe country should be preserved.

For tourism to be improved, the number of personnel who can use foreign languages is very important. A main source of problems in medical tourism is that medical personnel are not trained in foreign languages. This issue has been investigated in the news article "Language Training for MedicalPersonnel a Must"(Hürriyet, 26 October 2014). In the article, it was reported that medical personnel should be trained on Medical English and there might be problems to reach the goals because of the lack of medical personnel with language training. It was also emphasized that Arabic is another language that should be taught because of the number of Arab tourists visiting the country.

\section{Other News Pieces}

Other news articles in newspapers (3 articles) include articles that provide information about the meetings on this subject and facilities that are established. In the article "Invitation to Turkey for English Patients" (Hürriyet,11 May 2015), it was reported that the Ministry of Health is preparing to organize a London Medicine Summit to promote 
English patients to come to Turkey, and in the summit, some fields of expertise to be included are; organ transplantation, test tube babies, neurosurgery, ophthalmology, cardiology, orthopedics and traumatology, plastic surgery and dentistry and orthodontics. Thermal facilities opened in Afyon and Sakarya were reported in the article "Turkey's Goal: Health Tourism" (Hürriyet, 4 March 2015) and it was reported in the article "From Call Center to Health Tourism" (Hürriyet, 16 December 2014), the plan to establish a wellness\&spa hotel that will serve in the field of health tourism was announced.

\section{CONCLUSION}

In the research conducted, news articles published in newspapers between July 2014 and July 2015 were investigated. In the articles, the improvements of Turkish health tourism in an international sense, its current state of affairs, the economic uses that will be provided by health tourism and plans were reported, and information was given about events organized, and facilities established.

In the study, it has been found that Turkey is in a strong position in health tourism and the conflicts in the Arab world, the proximity to Europe and lower prices have been effective in this situation. With the supportive work of the government, health tourism in Turkey, which has been formed only of building hotels around hot springs, has been diversified as medical tourism and elderly tourism. Individuals are now visiting Turkey from abroad for organ transplants and serious surgeries. The economic value to be added by health tourism will be substantial when one takes into account the geographical location of Turkey, the trend to join the European Union, policies and the health transformation plan, the current state of the health sector as including in the Progress Plan and Programs, and improvements in tourism. Although health tourism is a sector that has great economic revenue, it also comprises unknown variables. As health tourism is a newly emerging concept in Turkey, there is not consistent statistical and academic work on the subject. There is no certain statistic about the amount of tourists that come to Turkey for health tourism, and the numbers are gathered from various reports with estimation.

It is seen on the news articles that events like fairs, summits and conventions provide basis to establish international health tourism partnerships. Increasing the government support on publicity and marketing, setting a basis for cooperation with other countries, and promoting advertising and providing information on Turkey's health system will contribute greatly to the encouragement of tourists to visit Turkey.

Another suggestion to improve health tourism is to place emphasis on foreign languages, and training especially the personnel to be included in medical services on medical terminology. For success in health tourism, in addition to quality of service and publicity, innovation is very important. Keeping up to date with international developments in medicine and establishing facilities in accordance, will increase the country's preferability. Additionally, the cooperation of the public and private sectors, non-governmental organizations and universities should be made stronger, and all institutions should satisfy certain standards in health tourism. Furthermore, health tourism related organizations should firstly decide in which group and to which market will health tourism work. Thermal tourism, elderly tourism, medical tourism, even in medical tourism firstly it should be decided whether it is latest technology treatment? Or plastic surgery? Or others? Finally, as a country if we are asserting to be a health tourism country the first and the easiest thing is to open ourselves to the market on hand. Countries like Turkish Republics, Afghanistan, Iraq, Syria and Middle East are close to us and also we have unity in culture. 
The organizations concerned with health tourism definitely should choose the market and health tourism group which is suitable for them.

\section{REFERENCES}

1. Azakl1, H. S., (2012). In Partial Fulfilment Of The Requirements For The Degree Of Master Of Science In City And Regional Plannıng.(A Thesis Submitted To The Graduate School Of Natural And Applied Sciences Of Middle East Technical University) https://etd.lib.metu.edu.tr/upload/12614842/index.pdf, (11.09.2015).

2. Barca, M., Akdeve, E., Gedik-Balay, İ. (2013). Türkiye sağlık Turizm Sektörünün Analizi ve Strateji Önerileri. İşletme Araştırmaları Dergisi, 5(3), 64-92.

3. Ciğerdelen, T. (2012). Sağlık Turizminde İnsan Kaynakları ve İletişim. 2nd Interdisciplinary Tourism Research Conference 12-15 April 2012, KemerAntalya.

4. Connel, J. (2006). Medical Tourism: Sea, Sun, Sand and Surgery. Tourism Management, 27, 1093-1100.

5. Gürel, E., Alem J. (2010). Postmodern Bir Durum Komedisi Üzerine İçerik Analizi: Simpsonlar. Uluslararası Sosyal Araştırmalar Dergisi, 3 (10), 335-336.

6. Littrell, M. A., Paige, R. C., \& Song, K. (2004). Senior travelers: Tourism activities and shopping behaviors. Journal of Vacation Marketing, 10, 348-362.

7. Özbek, T. (1991). Dünyada ve Türkiye'de Termal Turizmin Önemi. Anatolia Dergisi, C. 2, S.3., 15-29.

8. Smith, M., Puczkó, L. (2009) Health and Wellness Tourism, Oxford, UK: Elsevier Ltd.

9. http://www.ktbyatirimisletmeler.gov.tr/TR,11479/turkiyede-saglik-ve-termalturizm.html (10.09.2015).

10. http://dap.gov.tr/yeniDosyalar/Kaynaklar/odop/11.pdf, 10.09.2015. 